\title{
Kajian Pertumbuhan Bibit Belimbing pada Pemberian Beberapa Dosis Pupuk Majemuk NPK Dan Pupuk Daun
}

\section{(Growth Respond from Dewi Starfruit Seed in the Several Dosages Application of NPK Compound Fertilizer and Foliage Fertilizer)}

\author{
Refa Firgiyanto $^{1 *}$, Tri Harjoso ${ }^{2}$, dan Etik Wukir Tini ${ }^{2}$ \\ ${ }^{1}$ Program Studi Produksi Tanaman Hortikultura, Departemen Produksi Pertanian, Politeknik Negeri Jember \\ J1. Mastrip, Jember 68101, Indonesia \\ ${ }^{2}$ Program Studi Agroteknologi, Fakultas Pertanian, Universitas Jenderal Soedirman \\ Jl. dr. Soeparno Karangwangkal, Purwokerto 53123, Indonesia \\ *Email korespondensi: refa_firgiyanto@polije.ac.id
}

Diterima 20 Februari 2019/Disetujui 01 Maret 2019

\begin{abstract}
Good seedling from Dewi starfruit is obtained from the good parent tree and intensive maintenance such as fertilizing. The purpose of the study was to know the effect of NPK compound fertilizer and foliage fertilizer, as well as their interaction on the growth of Dewi starfruit seedlings. This experiment used Randomized Complete Blok Design (RCBD) with factorial design. The first factor was three dosages of NPK compound fertilizer i.e. 0, 20 and $40 \mathrm{~g} /$ plant. The second factor was three dosages of foliage fertilizer i.e. 0,1 and $2 \mathrm{~g} /$ plant. Variables observed were plant's height, stem diameter, the number of branch, the amount of primary branch root, the amount of leaves in one stem, leaves area, fresh and dry weight of roots and crown.

The results showed that NPK compound fertilizer was able to increase the growth of plant's height, stem diameter, amount to primary branch root, amount to leaves in one stem, leaves area, the fresh and dry weight of roots and crowns, but didn't increase the number of branches. The best result was obtained from NPK compound fertilizer with the dosages of 20 $\mathrm{g} /$ plant and $40 \mathrm{~g} /$ plant. Fertilizing with foliage fertilizer didn't influence of all growth variables of Dewi starfruit seedling, but the interaction between the dosages of NPK compound fertilizer and foliage fertilizer is able to increase the fresh and dry weight of the crown.
\end{abstract}

Keywords: Dewi, NPK, Foliage Fertilizer

\section{ABSTRAK}

Bibit Belimbing Dewi unggul didapatkan dari pohon induk yang baik dan pemeliharaan yang intensif seperti aplikasi pupuk majemuk NPK dan pupuk daun. Penelitian ini bertujuan untuk mengetahui dosis pupuk majemuk NPK dan pupuk daun yang paling tepat agar dapat memberikan pertumbuhan yang baik serta mengetahui interaksinya terhadap pertumbuhan bibit belimbing Dewi.

Penelitian dilaksanakan di Screen House Kebun Percobaan Fakultas Pertanian Universitas Jenderal Soedirman Purwokerto dengan ketinggian $110 \mathrm{~m}$ dpl. Rancangan percobaan yang digunakan yaitu Rancangan Acak Kelompok Lengkap (RAKL) faktorial. Faktor pertama yaitu tiga dosis pupuk majemuk NPK (0, 20 dan 40 g/tanaman), sedangkan faktor kedua tiga dosis pupuk daun (0, 1 dan 2 g/tanaman).

Hasil penelitian menunjukkan pemberian pupuk majemuk NPK dapat meningkatkan pertumbuhan tinggi tanaman, penambahan diameter batang, jumlah akar cabang primer, jumlah anak daun, luas daun, bobot segar dan kering tajuk dan tanaman, akan tetapi tidak meningkatkan jumlah cabang. Hasil terbaik diperoleh dari pemberian dosis pupuk majemuk NPK $20 \mathrm{~g} /$ tanaman atau $40 \mathrm{~g} /$ tanaman. Pemanfaatan dosis pupuk daun tidak mampu meningkatkan semua variabel pertumbuhan. Terdapat interaksi antara perlakuan pupuk majemuk NPK dan pupuk daun dengan bobot segar dan kering tajuk terbaik didapatkan pada pemberian dosis pupuk majemuk NPK $20 \mathrm{~g} /$ tanaman dengan pupuk daun 2 g/tanaman.

Kata kunci: Dewi, NPK, pupuk daun 


\section{PENDAHULUAN}

Hortikultura merupakan salah satu komoditas pertanian yang memiliki potensi besar untuk dikembangkan di Indonesia. Komoditas hortikultura terdiri atas 323 jenis tanaman meliputi 80 jenis sayuran, 66 jenis biofarmaka, 117 jenis tanaman hias dan 60 jenis buah-buahan. Belimbing merupakan jenis tanaman buah tropik yang banyak dibudidayakan di Indonesia karena mudah berbunga dan kandungan buahnya mengandung vitamin $\mathrm{C}$ lebih tinggi dibandingkan dengan apel dan anggur. Tanaman belimbing pada umumnya ditanam dalam bentuk kultur pekarangan (home yard gardening) atau dalam kebun yang berskala besar-besaran untuk tujuan ekspor dalam bentuk buah kalengan (Rukmana 1996) Pengolongan tanaman belimbing dapat terbagi menjadi belimbing manis dan belimbing wuluh. Belimbing manis memiliki beberapa keunggulan dibandingkan dengan belimbing wuluh antara lain kandungan energi dan gizi yang lebih besar serta memiliki varietas yang lebih banyak. Salah satu varietas belimbing manis adalah belimbing Dewi (Rukmana 1996).

Belimbing Dewi berasal dari daerah Pejaten, Pasar Minggu. Belimbing Dewi dikembangkan pertama kali oleh Ny. Permanasari pemilik PT. Dewi Jaya. Keunggulan belimbing Dewi yaitu tingkat kemanisan buah yang lebih tinggi dan berat buah yang besar karena memiliki kandungan air yang banyak serta memiliki bentuk tanama yang rimbun dan indah sehingga dapat ditanam dalam pot di depan rumah. Keunggulan ini menjadikan belimbing Dewi menjadi salah satu jenis belimbing unggul nasional dengan peningkatan permintaan buah dan bibit yang terus mengalami peningkatan.

Pembimbitan belimbing Dewi pada umumnya banyak dilakukan di dalam pot atau polibag dengan media tanam dengan kandungan hara yang terbatas. Oleh karena itu, diperlukan adanya penambahan unsur hara makro dan mikro dari luar melalui pemupukan untuk membantu dalam menjaga kesuburan tanah dan jumlah nutrisi yang diperlukan oleh tanaman (Nasreen et al. 2013) . Pupuk yang berikan dapat berupa pupuk tunggal yang hanya mengandung satu unsur makro maupun mengunakan pupuk majemuk yang mengandung lebih dari satu unsur makro yang dalam penggunaannya sangat dipengaruhi oleh tingkat pertumbuhan tanaman dan produktivitas tanaman (Ilupeju et al. 2011). Menurut Rukmana (1996), pemupukan tanaman belimbing dapat berupa campuran urea, TSP dan KCL (2:1:1) sebanyak 20 gram, sedangkan pemupukan mengunakan pupuk majemuk $\mathrm{N}, \mathrm{P}$ dan $\mathrm{K}$ secara langsung pada pembibitan belimbing sampai saat ini masih belum diketahui dosis yang paling tepat oleh sebab itu diperlukan adanya suatu kajian penelitian terkait pemberian dosis pupuk majemuk agar nantinya tidak berdampak negatif pada tanaman dan tanah seperti kerusakan struktur tanah dan matinya organisme tanah (Rosmarkam \& Yuwono 2002). Akmala (2011) melaporkan bahwa pemupukan NPK dengan dosis $30 \mathrm{~g} /$ tanaman berpengaruh terhadap peningkatan pertumbuhan panjang batang atas dan jumlah daun pada tanaman jambu Citra. Pemupukan majemuk NPK pada beberapa hasil penelitian juga telah mampu meningkatkan pertumbuhan dan produksi tanaman antara lain tanaman tomat (Subhan et al. 2009), labu (Okonwu \& Mensah 2012), mangga (Sarker \& Rahim 2012), jeruk (Nasreen et al. 2013), dan buah naga (Chakma et al. 2014), Sayur edamame (Fajrin et al. 2015) dan kedelai (Perkasa et al. 2016)

Pemupukan tanaman belimbing pada umumnya dilakukan dengan cara dibenamkan ke tanah dengan kedalam lebih kurang sedalam $10 \mathrm{~cm}$. Metode ini paling efektif digunakan untuk pemberian nutrisi dalam jumlah yang besar, akan tetapi dalam kondisi tertentu pemupukan juga dapat dilakukan dengan metode lain misalnya melalui penyemprotan ke daun dengan pupuk daun. Metode ini lebih ekonomis dan efektif pada kondisi tertentu (Fageria et al. 2009). Sarief (1986) melaporkan bahwa unsur hara yang diberikan untuk tanaman dapat diserap dengan cepat apabila disemprotkan pada daun karena dapat dengan mudah masuk melalui lubang stomata secara difusi maupun osmosis. Contoh pupuk daun yang banyak digunakan diantranya pupuk yang mengandung N 14\%, P 12\%, K 14\%, Mg 1\%, $\mathrm{Mn}, \mathrm{B}, \mathrm{Cu}, \mathrm{Co}$, dan $\mathrm{Zn}$. Manfaat pupuk ini yaitu untuk memacu pertumbuhan vegetatif pada tanaman. Pada aplikasinya pupuk daun juga memiliki kelemahan yaitu cepat menguap dan cepat terbawa angin, sehingga aplikasinya perlu diperhatikan dengan baik dosisnya, selain itu apabila dosisnya tidak tepat akan menyebabkan kerusakan pada daun seperti terbakar (Fageria et al. 2009). Dosis pupuk daun yang optimum pada pembibitan belimbing Dewi sampai saat ini masih belum ditemukan, oleh karena itu dibutuhkan penelitian terkait kajian tersebut. Pada penelitian yang telah dilakukan sesebelumnya oleh Akmala (2011) pemberian pupuk daun dengan dosis 1 $\mathrm{g} /$ tanaman mampu peningkatan batang atas tanaman jambu dengan rata-rata $36 \mathrm{~cm}$.

Tujuan dari penelitian ini yaitu 1) mengetahui dosis pupuk majemuk NPK yang paling tepat sehingga memberikan pertumbuhan yang terbaik pada bibit belimbing Dewi, 2) mengetahui dosis pupuk daun yang paling tepat sehingga memberikan pertumbuhan yang terbaik pada bibit belimbing Dewi, dan 3) mengetahui apakah terdapat interaksi antara dosis pupuk majemuk NPK dengan dosis pupuk daun yang berpengaruh terhadap pertumbuhan bibit belimbing Dewi.

\section{BAHAN DAN METODE}

Penelitian dilaksanakan di Screen House Kebun Percobaan Fakultas Pertanian Universitas Jenderal Soedirman, Kelurahan Grendeng Kecamatan Purwokerto Utara Kabupaten Banyumas dengan ketinggian tempat lebih kurang 110 meter dpl. Media tanam yang diguanakan yaitu campuran antara tanah dan sekam (2:1). Rancangan percobaan yang digunakan dalam penelitian ini adalah rancangan acak kelompok lengkap (RAKL) pola faktorial dengan tiga ulangan. Faktor yang dicoba terdiri atas tiga taraf dosis pupuk majemuk NPK dan pupuk daun. Dosis pupuk NPK meliputi dosis $0 \mathrm{~g} /$ tanaman, $20 \mathrm{~g} /$ tanaman dan $40 \mathrm{~g} /$ tanaman, sedangkan dosis pupuk daun meliputi 0 $\mathrm{g} /$ tanaman, $1 \mathrm{~g} / \mathrm{tanaman}$ dan $2 \mathrm{~g} /$ tanaman. Total kombinasi perlakuan dari kedua faktor adalah sembilan kombinasi 
dengan setiap unit percobaan terdiri atas tiga tanaman sehingga total tanaman yang digunakan berjumlah 81 tanaman.

Variabel yang diamati pada percobaan ini meliputi tinggi tanaman, jumlah daun dan cabang yang dilakukan setiap 2 minggu sekali sampai akhir penelitian. Variabel luas daun diukur dengan menggunakan metode kertas millimeter yaitu dengan cara mengambar sampel daun di atas kertas millimeter dengan mengikuti pola daun sesuai dengan metode Sitompul dan Guritno (1995). Variabel penambahan diameter batang dilakukan dengan menggunakan jangka sorong dengan ketinggan $10 \mathrm{~cm}$ dari titik okulasi pada awal dan akhir penelitian. Variabel selanjutnya yaitu jumlah akar cabang primer, bobot basah dan kering tanaakar dan tajuk yang dilakukan pada akhir penelitian. Data yang diperoleh dari hasil pengamatan kemudian dianalisis dengan uji $\mathrm{F}$ untuk mengetahui pengaruh faktor perlakuan yang dicoba. Apabila hasil uji F menyatakan Ho ditolak, berarti ada pengaruh dari perlakuan maka akan dilanjutkan dengan uji DMRT dengan tingkat kesalahan 5\% dan dilanjutkan juga dengan analisis regresi.

\section{HASIL DAN PEMBAHASAN}

Hasil analisis ragam menunjukkan adanya pengaruh yang nyata dari pemupukan majemuk NPK dalam meningkatkan pertumbuhan bibit belimbing meliputi tinggi tanaman, penambahan diameter batang, jumlah akar cabang primer, luas dan jumlah anak daun, bobot segar dan kering dari taju dan tanaman, sedangkan jumlah cabang tidak mengalami pengaruh yang nyata (Tabel 1). Pemberian dosis pupuk daun tidak berpengaruh nyata dalam meningkatkatkan seluruh variabel pertumbuhan bibit belimbing Dewi, sedangkan interaksi antar pemberian dosis pupuk daun dan dosis pupuk NPK berpengaruh nyata dalam meningkatkan bobot segar dan kering tajuk tanaman belimbing Dewi (Tabel 1).

\section{Pengaruh dosis pupuk majemuk NPK}

Pemupukan adalah pemberian bahan yang dimaksudkan untuk menyediakan hara bagi tanaman yang berupa pupuk majemuk atau pupuk tunggal (Rosmarkam dan Yuwono, 2002). Keunggulan pupuk majemuk terdapat pada tingkat kepraktisannya dibandingkan pupuk tunggal karena hanya dengan satu kali penebaran, beberapa unsur hara dapat tersedia secara bersama-sama. Hasil penelitian menunjukkan adanya peningkatkan pertumbuhan tanaman belimbing Dewi setelah diaplikasikan pupuk majemuk NPK. Tanaman belimbing Dewi tertinggi didapatkan pada perlakuan dosis $20 \mathrm{~g} /$ tanaman yang tidak berbeda nyata dengan perlakuan dosis $40 \mathrm{~g} /$ tanaman. Tinggi tanaman belimbing dewi yang diaplikasikan dengan pupuk majemuk NPK lebih tinggi 43,7 - 45,8\% dibandingkan dengan dosis pemupukan $0 \mathrm{~g} /$ tanaman. Jumlah daun, luas daun dan pertambahan diameter batang juga menunjukkan adanya peningkatan pertumbuhan. Jumlah daun terbanyak diperoleh pada perlakuan pemupukan $20 \mathrm{~g} / \mathrm{tanaman}$ dan $40 \mathrm{~g} / \mathrm{tanaman}$ dengan jumlah lebih banyak $52 \%$ dibandingkan dengan perlakuan pemupukan $0 \mathrm{~g} /$ tanaman, sedangkan luas daun terluas diperoleh pada perlakuan $20 \mathrm{~g} /$ tanaman dan 40 g/tanaman dengan luasan daun lebih luas 35,35 - 38,61\% dibandingkan dengan dosis pemupukan $0 \mathrm{~g} / \mathrm{tanaman}$ (Tabel 2). Peningkatan diameter batang terbaik juga diperoleh pada pemupukan majemuk NPK pada dosis $20 \mathrm{~g} /$ tanaman dan 40 g/tanaman dengan peningkatan diameter sebesar 75,9\% dibandingkan dengan dosis $0 \mathrm{~g} /$ tanaman (Tabel 2).

Tabel 1. Matrik hasil analisis ragam data percobaan

\begin{tabular}{|c|c|c|c|c|}
\hline No & Variabel yang diamati & $\mathrm{P}$ & $\mathrm{D}$ & P X D \\
\hline 1 & Tinggi tanaman $(\mathrm{cm})$ & $\mathrm{sn}$ & tn & tn \\
\hline 2 & Jumlah cabang & tn & tn & $\operatorname{tn}$ \\
\hline 3 & Penambahan diameter batang $(\mathrm{cm})$ & sn & tn & tn \\
\hline 4 & Jumlah akar cabang primer & sn & tn & tn \\
\hline 5 & Luas daun $\left(\mathrm{cm}^{2}\right)$ & sn & $\operatorname{tn}$ & tn \\
\hline 6 & Jumlah anak daun & sn & tn & tn \\
\hline 7 & Bobot segar tajuk (g) & sn & tn & $\mathrm{n}$ \\
\hline 8 & Bobot segar akar (g) & sn & tn & tn \\
\hline 10 & Bobot kering tajuk $(\mathrm{g})$ & sn & tn & $\mathrm{n}$ \\
\hline 11 & Bobot kering akar $(\mathrm{g})$ & $\mathrm{n}$ & tn & tn \\
\hline
\end{tabular}

Keterangan:

$\begin{array}{ll}\text { P } & \text { : Dosis pupuk majemuk NPK } \\ \text { D } & \text { : Dosis pupuk daun } \\ \text { P X D } & \text { : Interaksi dosis pupuk majemuk NPK dan pupuk daun } \\ \text { tn } & \text { : Tidak nyata } \\ \text { sn } & \text { : Sangat nyata } \\ \text { n } & \text { : Nyata }\end{array}$


Tabel 2. Hasil DMRT pengaruh dosis NPK dan pupuk daun terhadap variabel pertumbuhan bibit belimbing Dewi

\begin{tabular}{|c|c|c|c|c|c|c|c|c|c|c|}
\hline \multirow[b]{2}{*}{ Data Perlakuan } & \multicolumn{10}{|c|}{ Variabel Pertumbuhan } \\
\hline & $\begin{array}{l}\mathrm{TT} \\
(\mathrm{cm})\end{array}$ & $\begin{array}{c}\mathrm{LD} \\
\left(\mathrm{cm}^{2}\right)\end{array}$ & $\mathrm{JAD}$ & $\mathrm{JC}$ & PDB & JACP & $\begin{array}{c}\text { BSA } \\
(\mathrm{g})\end{array}$ & $\begin{array}{c}\text { BSTj } \\
(\mathrm{g})\end{array}$ & $\begin{array}{c}\text { BKA } \\
(\mathrm{g})\end{array}$ & $\begin{array}{c}\text { BKTj } \\
(\mathrm{g})\end{array}$ \\
\hline \multicolumn{11}{|l|}{$\begin{array}{c}\text { Dosis pupuk majemuk } \\
\text { NPK }\end{array}$} \\
\hline $\mathrm{P}_{0}(0 \mathrm{~g} /$ tanaman $)$ & $45.079 \mathrm{~b}$ & $15.9 \mathrm{~b}$ & $325.89 \mathrm{~b}$ & 4.778 & $1.010 \mathrm{~b}$ & $38.3 \mathrm{~b}$ & $161.1 \mathrm{~b}$ & $211.1 \mathrm{~b}$ & $17.56 \mathrm{~b}$ & $21.44 \mathrm{~b}$ \\
\hline $\mathrm{P}_{1}(20 \mathrm{~g} /$ tanaman $)$ & $83.282 \mathrm{a}$ & $25.6 \mathrm{a}$ & $681.20 \mathrm{a}$ & 5.147 & $4.190 \mathrm{a}$ & $56.9 \mathrm{a}$ & 316.7 a & $631.1 \mathrm{a}$ & $29.44 \mathrm{a}$ & $59.78 \mathrm{a}$ \\
\hline $\mathrm{P}_{2}(40 \mathrm{~g} /$ tanaman $)$ & $80.154 \mathrm{a}$ & $24.6 \mathrm{a}$ & $680.00 \mathrm{a}$ & 5.629 & $4.199 \mathrm{a}$ & 58.9 a & 306.7 a & $630.0 \mathrm{a}$ & $28.33 \mathrm{a}$ & 58.33 a \\
\hline F hit P & $\begin{array}{c}99.26 \\
* *\end{array}$ & $\begin{array}{c}25.58 \\
* *\end{array}$ & $\begin{array}{c}33.33 \\
* *\end{array}$ & 1.53 & $\begin{array}{c}92.98 \\
* *\end{array}$ & $\begin{array}{c}10.40 \\
* *\end{array}$ & $\begin{array}{c}9.99 \\
* *\end{array}$ & $240.72 * *$ & $\begin{array}{c}5.85 \\
*\end{array}$ & $208.42 * *$ \\
\hline \multicolumn{11}{|l|}{ Dosis pupuk daun } \\
\hline $\mathrm{D}_{0}(0 \mathrm{~g} / \mathrm{tanaman})$ & 66.840 & 21.3 & 576.741 & 5.777 & 3.436 & 53.2 & 236.7 & 477.5 & 20.56 & 44.56 \\
\hline $\mathrm{D}_{1}(1 \mathrm{~g} /$ tanaman $)$ & 69.851 & 22.2 & 530.187 & 4.813 & 2.864 & 44.0 & 244.4 & 496.7 & 24.56 & 47.22 \\
\hline $\mathrm{D}_{2}(2 \mathrm{~g} /$ tanaman $)$ & 71.824 & 22.4 & 580.166 & 4.963 & 3.099 & 56.9 & 303.3 & 500.0 & 30.22 & 47.78 \\
\hline hit D & 1.39 & 0.31 & 0.62 & 2.26 & 2.28 & 3.57 & 1.75 & 0.55 & 3.21 & 1.31 \\
\hline
\end{tabular}

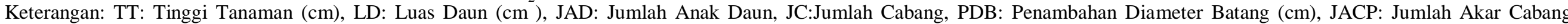
Primer, BSTj: Bobot Segar Tajuk (g), BSA: Berat Segar Akar (g), BBTj: Bobot Kering Tajuk (g), BKA: Bobot Kering Akar (g). Angka yang diikuti huruf yang sama pada kolom yang sama tidak berbeda nyata pada DMRT 5\% dan (**) menunjukkan berbeda sangat nyata dan (*) menunjukkan berbeda nyata pada kolom yang sama pada DMRT $5 \%$. 
Jumlah akar cabang cabang primer terbaik berdasarkan hasil penelitian didapatkan pada pemberian pupuk majemuk NPK dengan dosis $40 \mathrm{~g} /$ tanaman yang tidak berbeda nyata dengan perlakuan dosis $20 \mathrm{~g} / \mathrm{tanaman}$, sedangkan bobot segar dan kering akar dan tajuk tanaman belimbing Dewi didapatkan pada pemupukan majemuk NPK dengan dosis $20 \mathrm{~g} /$ tanaman yang tidak berbeda nyata dengan perlakuan dosis $40 \mathrm{~g} / \mathrm{tanaman}$ (Tabel 2). Perbandingan jumlah akar cabang primer pada perlakuan pemupukan majemuk NPK $40 \mathrm{~g} /$ tanaman dan $20 \mathrm{~g} /$ tanaman lebih banyak $32,7-34,9 \%$ dibandingkan dengan pemupukan pada dosis 0 g/tanaman. Bobot segar akar dan kering pada pemberian dosis pemupukan majemuk NPK 20 g/tanaman dan 40 g/tanaman lebih besar 47,5 - 49,1\% dan $38-40,35 \%$ dibandingkan dengan pemupukan $0 \mathrm{~g} / \mathrm{tanaman}$, sedangkan bobot segar tajuk tanaman belimbing dewi berdasarkan hasil penelitian lebih besar $66,5 \%$ dan bobot kering tajuk lebih besar 63,24 - 64,13\% dibandingkan dengan dosis pemupukan $0 \mathrm{~g} /$ tanaman (Tabel 2).

Nitrogen merupakan salah satu unsur hara esensial yang bersifat sangat mobil, baik di dalam tanah maupun di dalam tanaman. Unsur hara $\mathrm{N}$ berpengaruh pada produksi klorofil dalam tanaman sehingga proses metabolisme dapat berjalan dengan lancar, selain itu unsur hara $\mathrm{N}$ juga berperan dalam memproduksi protein dan enzim yang berpengaruh pada pertumbuhan vegetatif (Okonwu \& Mensah 2012). Kekurangan unsur $\mathrm{N}$ pada tanaman akan mengakibatkan pertumbuhan tanaman tidak optimal dan menurunkan produktifitasnya.

Unsur $\mathrm{P}$ mempunyai peranan penting dalam perkembangan horisontal tanaman, proses fisiologis, penyusun protoplasma dan intisel (Ernawati 2011). Kekurangan unsur ini akan menyebabkan pertumbuhan tanaman menjadi kerdil, penghambatan perkembangan akar dan cabang serta perlambatan waktu panen (Subhan et al. 2009). Unsur K pada pemberian pemupukan majemuk NPK memiliki peran penting dalam metabolisme air dalam tanaman, absorpsi hara tanah, transpirasi, kerja enzim dan translokasi karbohidrat serta ketahanan terhadap penyakit. Tanaman yang kekurangan usur ini selama pertumbuhan dapat menyebabkan tanaman muda rebah karena batang yang lemah dan penurunan ketahanan terhadap penyakit (Burket et al.2003).Hasil penelitian yang berpengaruh nyata pada pemberian pemupukan NPK ini juga didukung oleh penelitian Omotosa dan Shittu (2007) yang melaporkan bahwa pemupukan majemuk NPK berperan dalam meningkatkan pertumbuhan vegetatif tanaman okra, LawOgbomo dan Law-ogbomo (2009); Asghar et al. (2010); Kasno dan Rostaman (2013) pemberian pupuk NPK dapat meningkatkan pertambahan tinggi dan hasil tanaman jagung, Okonwu \& Mensah (2012) pemberian pupuk NPK juga dapat meningkatan luas dan jumlah daun, diameter batang dan bobot segara dan kering dari tanaman labu dibandingkan kontrol. Pemanfaatan dosis pupuk majemuk NPK yang tidak berpengaruh dalam meningkatkan jumlah cabang, diduga disebabkan karena pasokan unsur hara $\mathrm{N}, \mathrm{P}$ dan $\mathrm{K}$ terpusat untuk pertumbuahan variabel lainya. Menurut Marschner (1993), apabila suatu variabel pertumbuhan tidak optimum maka pertumbuhan organ lainya akan optimum.

\section{Pengaruh dosis pupuk daun}

Hasil penelitian pemberian dosis pupuk daun pada tanaman belimbing dewi belum mampu meningkatkan seluruh variabel pertumbuhan tanaman secara signifikan (Tabel 1 dan 2). Hal tersebut diduga karena dosis pupuk daun yang diberikan dengan dosis $1 \mathrm{~g} / \mathrm{tanaman}$ dan 2 g/tanaman masih belum mampu dalam mencukupi kebutuhan penyerapan unsur hara melalui daun. Hasil penelitian yang tidak berbeda nyata tidak lepas juga dari peranan pupuk daun yang diguanakan hanya sebagai pupuk tambahan atau pupuk penunjang pertumbuhan tanaman. Lingga \& Marsono (2007) menyatakan bahwa penambahan unsur hara melalui daun hanya berperan sebagai pelengkap saja apabila unsur hara di dalam tanah sudah terpenuhi oleh adanya pemupukan melalui tanah, sedangkan menurut Saberan et al. (2014) menyebutkan bahwa ketidaksesuai konsentrasi larutan pupuk daun dapat menyebabkan penurunan efektivitasnya. Penurunan efektivitas tersebut juga didukung oleh tingkat pengupan pupuk yang cukup tinggi apabila dilakukan pada waktu yang tidak tepat (Lingga \& Marsono 2007).

\section{Pengaruh interaksi antara dosis pemupukan majemuk NPK dengan pupuk daun}

Hasil penelitian menunjukkan adanya interaksi dosis pupuk majemuk NPK dan pupuk daun yang berpengaruh nyata dalam meningkatkan bobot segar tajuk dan bobot kering tajuk. Bobot segar tajuk terbaik didapatkan pada perlakuan dosis pupuk majemuk NPK $20 \mathrm{~g} /$ tanaman dengan pemberian dosis pupuk daun $2 \mathrm{~g} /$ tanaman yang tidak berbeda nyata dengan pemberian dosis pemupukan majemuk NPK $20 \mathrm{~g} /$ tanaman tanpa diberi pupuk daun (0 g/tanaman) dan dosis pemupukan majemuk NPK $40 \mathrm{~g} /$ tanaman yang diberi pupuk daun pada dosis $2 \mathrm{~g} /$ tanaman dengan bobot lebih besar 74,74-75,38\% dibandingkan pemberian pupuk majemuk NPK dan pupuk daun $0 \mathrm{~g} /$ tanaman atau tanpa dipupuk (Tabel 3).

Bobot kering tajuk terbaik didapatkan pada pemberian pemupukan majemuk NPK $20 \mathrm{~g} / \mathrm{tanaman}$ dan pemberian pupuk daun $2 \mathrm{~g} /$ tanaman. Perbandingan bobot kering pada interaksi kedua perlakuan lebih besar 73,61\% dibandingkan pemberian pupuk majemuk NPK dan pupuk daun $0 \mathrm{~g} /$ tanaman atau tanpa dipupuk (Tabel 4).

Pemupukan majemuk NPK dengan perbandingan (15:15:15) dan pupuk daun yang mengandung $\mathrm{N} 14 \%, \mathrm{P}$ $12 \%, \mathrm{~K} 14 \%, \mathrm{Mg} 1 \%, \mathrm{Mn}, \mathrm{B}, \mathrm{Cu}, \mathrm{Co}$, dan $\mathrm{Zn}$ berperan dalam menyediakan unsur hara makro dan mikro yang secara bersama-sama saling melengkapi guna pertumbuhan tanaman belimbing Dewi yang terbukti dengan pengaruh interaksi yang nyata pada bobot segar dan kering tajuk tanaman belimbing Dewi. Dhenianti (2008) dan Saberan et al. (2014) melaporkan bahwa unsur hara makro yang berasal dari pupuk majemuk NPK maupun unsur hara mikro yang berasal dari pupuk daun misalnya $\mathrm{B}, \mathrm{Cu}$, $\mathrm{Co}$ dan $\mathrm{Zn}$ yang meskipun jumlahnya rendah berperan ketersediaan unsur hara. 
Tabel 3. Hasil DMRT interaksi dosis pupuk majemuk NPK dan pupuk daun terhadap bobot segar tajuk

\begin{tabular}{clll}
\hline Dosis Pupuk majemuk NPK & \multicolumn{3}{c}{ Dosis pupuk daun (g/tanaman) } \\
\cline { 2 - 4 } (g/tanaman) & D0 & D1 & D2 \\
\hline PO & $163.3 \mathrm{c} \mathrm{C}(\mathrm{g})$ & $280.0 \mathrm{c} \mathrm{A} \mathrm{(e)}$ & $190.0 \mathrm{~b} \mathrm{~B} \mathrm{(f)}$ \\
P1 & $656.3 \mathrm{a} \mathrm{A} \mathrm{(ab)}$ & $573.3 \mathrm{~b} \mathrm{~B} \mathrm{(d)}$ & $663.3 \mathrm{a} \mathrm{A} \mathrm{(a)}$ \\
P2 & $606.7 \mathrm{~b} \mathrm{~B} \mathrm{(c)}$ & $636.7 \mathrm{a} \mathrm{A} \mathrm{(b)}$ & $646.7 \mathrm{a} \mathrm{A} \mathrm{(ab)}$ \\
\hline
\end{tabular}

Keterangan: $\mathrm{P}_{0}: 0 \mathrm{~g} /$ tanaman, $\mathrm{P}_{1}: 20 \mathrm{~g} / \operatorname{tanaman}, \mathrm{P}_{2}: 40 \mathrm{~g} / \operatorname{tanaman} . \mathrm{D}_{0}: 0 \mathrm{~g} / \operatorname{tanaman}, \mathrm{D}_{1}: 1 \mathrm{~g} / \operatorname{tanaman}, \mathrm{D}_{2}: 2 \mathrm{~g} / \operatorname{tanaman}$. Angka

yang diikuti huruf kapital yang sama pada baris yang sama tidak berbeda nyata pada DMRT taraf kesalahan $5 \%$, angka yang diikuti huruf kecil yang sama pada kolom yang sama tidak berbeda nyata pada DMRT taraf kesalahan 5\%, angka yang diikuti huruf kecil dalam tanda kurung yang sama tidak berbeda nyata pada DMRT taraf kesalahan $5 \%$.

Tabel 4. Hasil DMRT interaksi dosis pupuk majemuk NPK dan pupuk daun terhadap bobot kering tajuk

Dosis Pupuk majemuk NPK (g/tanaman) Dosis pupuk daun (g/tanaman)

\begin{tabular}{llll} 
& \multicolumn{1}{c}{ D0 } & \multicolumn{1}{c}{ D1 } & D2 \\
PO & $16.7 \mathrm{c} \mathrm{C}(\mathrm{f})$ & $28.3 \mathrm{~b} \mathrm{~A} \mathrm{(d)}$ & $19.3 \mathrm{c} \mathrm{B} \mathrm{(e)}$ \\
P1 & $60.0 \mathrm{a} \mathrm{B} \mathrm{(b)}$ & $56.0 \mathrm{a} \mathrm{C} \mathrm{(c)}$ & $63.3 \mathrm{a} \mathrm{A} \mathrm{(a)}$ \\
P2 & $57.0 \mathrm{~b} \mathrm{~B} \mathrm{(c)}$ & $57.3 \mathrm{a} \mathrm{B} \mathrm{(c)}$ & $60.7 \mathrm{~b} \mathrm{~A} \mathrm{(b)}$
\end{tabular}

Keterangan: $\mathrm{P}_{0}: 0 \mathrm{~g} / \operatorname{tanaman}, \mathrm{P}_{1}: 20 \mathrm{~g} / \operatorname{tanaman}, \mathrm{P}_{2}: 40 \mathrm{~g} / \operatorname{tanaman} . \mathrm{D}_{0}: 0 \mathrm{~g} / \operatorname{tanaman}, \mathrm{D}_{1}: 1 \mathrm{~g} / \operatorname{tanaman}, \mathrm{D}_{2}: 2 \mathrm{~g} / \operatorname{tanaman}$. Angka yang diikuti huruf kapital yang sama pada baris yang sama tidak berbeda nyata pada DMRT taraf kesalahan $5 \%$, angka yang diikuti huruf kecil yang sama pada kolom yang sama tidak berbeda nyata pada DMRT taraf kesalahan 5\%, angka yang diikuti huruf kecil dalam tanda kurung yang sama tidak berbeda nyata pada DMRT $5 \%$ taraf kesalahan.

Penyerapan dan ketersedian hara dan air yang terpenuhi akan meningkatkan laju pertumbuhan vegetatif terutama tajuk dari tanaman yang berasal dari penyerapan melalaui akar dan melalui daun karena adanya peningkatan aktivitas metabolisme, pembelahan sel dan transformasi energi yang berjalan dengan baik (Nasreen et al. 2007). Gardner (2011) menyatakan bahwa bobot kering tanaman merupakan cerminan dari jumlah penyerapan unsur hara dan pemanfaatan radiasi matahari yang tersedia selama pertumbuhan. Penambahan pertumbuhan ujung lebih digalakkan apabila tersedia $\mathrm{N}$ dan air yang banyak sebaliknya apabila faktor-faktor $\mathrm{N}$ dan air ini terbatas pertumbuhan akar akan lebih digalakkan.

Pemberian dosis pupuk majemuk NPK dan pupuk daun tidak menunjukkan adanya interaksi pengaruh yang nyata terhadap pertumbuhan tinggi tanaman, jumlah cabang, penambahan diameter batang, jumlah akar cabang primer, luas daun, jumlah anak daun, bobot segar dan kering dari akar dan tanaman, hal ini disebabkan oleh pengaruh dari masing-masing faktor perlakuan sacara mandiri yang lebih berpengaruh dari pada faktor interaksinya seperti pada hasil penelitian Perkasa (2016). Steel dan Torrie (1991) juga menyatakan bahwa bila pengaruh interaksi berbeda tidak nyata, maka disimpulkan bahwa diantara faktor-faktor perlakuan tersebut bertindak bebas atau pengaruhnya berdiri sendiri.

\section{KESIMPULAN}

1. Pemberian pupuk majemuk NPK dapat meningkatkan pertumbuhan tinggi tanaman, penambahan diameter batang, jumlah akar cabang primer, jumlah anak daun, luas daun, bobot segar akar dan tanaman, serta bobot kering akar dan tanaman, akan tetapi pemberian dosis pupuk majemuk NPK tidak mampu meningkatkan jumlah cabang. Dosis pemupukan majemuk NPK terbaik diperoleh pada pemberian dosis $20 \mathrm{~g} / \mathrm{tanaman}$.

2. Pemberian berbagai dosis pupuk daun belum mampu meningkatkan pertumbuhan bibit belimbing Dewi.

3. Terdapat adanya interaksi antara pemberian dosis pupuk majemuk NPK dan pupuk daun yang mampu meningkatkan bobot segar tajuk dan bobot kering tajuk. Bobot segar dan kering tajuk terbaik didapatkan pada pemberian dosis pupuk majemuk NPK 20 $\mathrm{g} /$ tanaman dengan pupuk daun $2 \mathrm{~g} /$ tanaman.

\section{DAFTAR PUSTAKA}

Akmala I. 2011. Kajian pemanfaatan dosis pupuk npk dan pupuk daun terhadap pertumbuhan bibit okulasi tanaman jambu air varietas citra Syzygium samarangense (Blume) Merr. Skripsi. Fakultas Pertanian, Universitas Jendral Soedirman, Purwokerto. 52 hal (tidak dipublikasikan)

Al-Mukhtar F.A., Hummadi F.M. , Al-Sahaf F.H. 1988. Effect of different levels of NPK fertilizer on growth and yield of two summer squash cultivars. Acta Hort. 220: 253-258.

Asghar A., Ali A., Syed W.H., Asif M., Khaliq T., Abid A.A. 2010. Growth and yield of maize (Zea mays L.) 
cultivars affected by NPK application in different proportion. Pakistan J. of Sci. 62(4): 211-216.

Awadun M.A., Omanijo L.I., Ojeniyi S.O. 2007. Effect of goat dung and NPK Fertilizer on soil and leaf nutrient content, growth, and yield of papper. Int. J. Soil. Sci. 2:142-147

Burket J.Z., Eemphill D.D., Dick. 2003. Wenter corer and potassium management in sweet corn and broccoli rotation. Hort. Sci. 32(4):64-68.

Chakma S.P., Rashid A.S.M.H., Roy. S., Islam M. 2014. Effect of NPK doses on the yield of dragon fruit (Hylocereus costaricensis [F.A.C. Weber] Britton \& Rose) in Chittagong Hill Tracts. American-Eurasian J. Agric. \& Environ. Sci.14(6): 521-526

Dhenianti, I. M. 2008. Pengaruh Jenis Pupuk Daun dan Dosis Pupuk NPK terhadap Pertumbuhan Adenium (Adenium sp). Skripsi. Fakultas Pertanian, Universitas Jendral Soedirman, Purwokerto (tidak dipublikasikan).

Ermawati. 2011. Respon Agronomis Bibit Tanaman Kakao terhadap Pemberian Beberapa Dosis Biochar dan Pupuk NPK Majemuk pada Tanah Pasir Pantai. Skripsi. Fakultas Pertanian, Universitas Jendral Soedirman, Purwokerto. 52 hal (tidak dipublikasikan)

Fageria N.K., Filho M.P.B., Moreira A. Guimarees C.M. 2009. Foliar fertilization of crop plants. J. of Plant Nutrition. 32(6): 1044-1064.

Fajrin A., Suryawati S., Sucipto. 2015. Respon tanaman kedelai sayur edamame terhadap perbedaan jenis pupuk dan ukuran jarak tanam. Agrivigor 8(2): 57-62.

Gardner F.P., Pearce R.B., Mitchell R.L. (1985). Physiology of Crop Plants. Ames: Iowa State University. 478 pp.

Ilupeju E.A.O., Akanbi W.B.1., Olaniyi J.O., Lawal B. A., Ojo M. A., Akintokun P.O. 2011. Impact of organic and inorganic fertilizers on growth, fruit yield, nutritional and lycopene contents of three varieties of tomato (Lycopersicon esculentum (L.) Mill) in Ogbomoso, Nigeria. African J. of Biotech. 14 (31): 2424-2433

Kasno, Rostaman. 2013. Serapan hara dan peningkatan produktivitas jagung dengan aplikasi pupuk npk majemuk. penelitian pertanian tanaman pangan. 32(3): 180-186

Kumar, A., S. Johari and S. Roy, 1995. Production and improvement of bioenergy sources. J. Indian Bot. Soc. 74: 233-244.
Law-Ogbomo K.E., Law-Ogbomo J.E., 2009. The performance of Zea mays as influenced by NPK fertilizer application. Not. Sc. Biol. 1(1): 59-62.

Lingga P., Marsono. 2007. Petunjuk Penggunaan Pupuk. Penebar Swadaya. Jakarta.

Liu W., Zhu D., Liu D., Geng M., Zhou W., Mi W., Yang T., Hamilton D.P., 2010. Influence of nitrogen on the primary and secondary metabolism and synthesis of flavonoids in Chrysanthemum morifolium Ramat. J.Pl Nutr. 33(2): 240-254.

Marscher, H. 1993. Mineral Nutrition of Higher Plants. Academy Press. San Diego CA 92101.674 p.

Martinetti L. Paganini F. 2006. Effect of organic and mineral fertilization on yield and quality of zucchini. Acta Hort. 700: 125-128.

Mawardiana, Sufardi, Husen E. 2013. Pengaruh Residu Biochar dan Pemupukan NPK terhadap Dinamika Nitrogen, Sifat Kimia Tanah dan Hasil Tanaman Padi (Oryza sativa L.) Musim Tanam Ketiga. J. Manajemen Sumberdaya Lahan. 2(3): 255-260

Nasreen N., Ahmed R., Ullah M.A., Hoque M.A. 2013. Effect of $\mathrm{N}, \mathrm{P}, \mathrm{K}$ and $\mathrm{Mg}$ application on yield and fruit quality of mandarin (Citrus reticulata). Bangladesh J. Agric. Res. 38(3): 425-433.

Nasreen S., Haque M.M., Hossain M.A. 2007. Nutrient uptake and yield of onion as influenced by nitrogen and sulphur fertilization. Bangladesh J. Agril. Res. 32(3) : 413-420

Nasreen S., Ahmed R., Ullah M.A., Hoque M.A. 2013. Effect of $\mathrm{N}, \mathrm{P}, \mathrm{K}$, and $\mathrm{Mg}$ application on yield and fruit quality of Mandarin (Citrus reticulata). Bangladesh J. Agril. Res. 38(3): 425-433,

Okonwu K., Mensah S.I. 2012. Effects of NPK (15: 15: 15) Fertilizer on some growth indices of pumpkin. Asian J. Of Agri. Res. 6(3): 137-143

Omotoso S.O., Shittu O.S. 2007. Effect of NPK fertilizer rates and method of application on growth and yield of Okra (Abelmoschus esculantus (L.) Moench) at Ado-Ekiti Saouthwestern. Nogeria. Int. J. Agric. Res. 2:614-619

Perkasa A.Y., Utomo, Widiatmoko T. 2016. Effect of Various Levels of NPK Fertilizer on the yield attributes of soybean (Glycine $\max$ L.) varieties. J. of Trop. Crop Sci. 3(1):7-12

Rosmarkam A., Yuwono N.W. 2002. Ilmu Kesuburan Tanah. Fakultas Pertanian Universitas Gadjah Mada. Yogyakarta. 
Rukmana R. 1996. Belimbing. Kanisius. Yogyakarta.

Saberan N. Rahmi A. Syhfari H. 2014. Pengaruh pupuk NPK Pelangi dan pupuk daun Grow Team terhadap pertumbuhan dan hasil tanaman tomat (Lycopersicon esculentum L. mill) varietas permata. J. Agrifor. 13(1): 67-74

Sarief S. 1986. Kesuburan dan Pemupukan Tanah Pertanian. Pustaka Buana. Bandung.

Sarker B, Rahim M.A. 2012. Effects of doses and splits of fertilizer application on harvesting time, yield and quality of mango CV. Amrapali. Bangladesh J. Agril. Res. 37(2): 279-293

Steel R.G.D., Torrie J. H. 1991. Prinsip dan Prosedur Statistika Suatu Pendekatan Biometrik. PT Gramedia. Jakarta

Subhan, Nurtika N., Gunadi N. 2009. Respons tanaman tomat terhadap penggunaan pupuk majemuk NPK 15-15-15 pada tanah latosol pada musim kemarau. J. Hort. 19(1): 40-48 